\title{
Influence of the worn tool affected by built-up edge (BUE) on micro end-milling process performance: A 3D finite element modeling investigation
}

\author{
Davoudinejad, Ali; Tosello, Guido; Annoni, Massimiliano
}

Published in:

International Journal of Precision Engineering and Manufacturing

Link to article, DOI:

$10.1007 / \mathrm{s} 12541-017-0157-6$

Publication date:

2017

Document Version

Peer reviewed version

Link back to DTU Orbit

Citation (APA):

Davoudinejad, A., Tosello, G., \& Annoni, M. (2017). Influence of the worn tool affected by built-up edge (BUE) on micro end-milling process performance: A 3D finite element modeling investigation. International Journal of Precision Engineering and Manufacturing, 18(10), 1321-1332. https://doi.org/10.1007/s12541-017-0157-6

\section{General rights}

Copyright and moral rights for the publications made accessible in the public portal are retained by the authors and/or other copyright owners and it is a condition of accessing publications that users recognise and abide by the legal requirements associated with these rights.

- Users may download and print one copy of any publication from the public portal for the purpose of private study or research.

- You may not further distribute the material or use it for any profit-making activity or commercial gain

- You may freely distribute the URL identifying the publication in the public portal 


\title{
Influence of the worn tool affected by built-up edge (BUE) on micro end-milling process performance: a 3D finite element modeling investigation
}

\author{
A. Davoudinejad $1, \#$, G. Tosello1, M. Annoni²
}

1 Department of Mechanical Engineering, Technical University of Denmark, Building 427A, Produktionstorvet, 2800 Kgs. Lyngby, Denmark 2 Mechanical Engineering Department, Politecnico di Milano, Via La Masa 1, 20156. Milan, Italy \# Corresponding Author / E-mail: alidav@mek.dtu.dk

KEYWORDS : Micro milling, finite element modeling, built-up edge, chip flow, burr formation

\begin{abstract}
Micro milling process has been utilized for several decades due to the flexibility of the process in producing complex components. The small size of the process makes the comprehension of cutting phenomenon details more difficult. This study presents a 3D finite element modeling (3D FEM) approach for the micro end-milling process of Aluminum material (Al6082T6). 3D FEM simulations are carried out in full slot micro end-milling and contour up milling. The model first implements the actual tool geometry and then the effect of typical built-up edge (BUE) on the milling tool. The influence of BUE on the process performance is investigated by comparing the predicted $3 d$ chip flow shape, burr formation and cutting forces with experiments conducted on an ultra-high precision micro milling center. Simulations indicate that BUE has significant impact on the chip shape and chip load for different teeth engagements. Results prove that also burr height is negatively affected by the presence of BUE. The predicted micro milling cutting forces resulted affected by BUE with different teeth engagements. Analysis of experimental measured forces indicates comparable results in respect to simulated profiles confirming the usefulness of the develop 3D FE modelling approach.
\end{abstract}

$\tau=$ frictional stresses
$\sigma_{n}=$ normal stresses
$\mu=$ coefficient of friction
$\sigma=$ material flow stress
$h_{f}=$ Burr height
$r_{\varepsilon}=$ corner radius
$r_{\mathrm{e}}=$ cutting edge radius
$f_{\mathrm{z}}=$ feed rate

\section{Introduction}

Micro milling operations are an efficient method for producing miniaturized components with 3D shapes in a flexible and cost efficient way [1]. Due to the small machining scale, the experimental investigations can become challenging and many problems usually considered negligible in macro scale machining can a major role in micro milling. In micro machining process size effect and minimum chip thickness phenomenon cause ploughing, and for these reasons associated material the flow pattern and elastic-plastic deformation along the rounded cutting edge start to 
play a dominant role in determining machining performance [2]. The bulk of chip formed in the cutting edge area is named as built-up edge (BUE) and these adhered materials on the tool face have a large influence on the machining process [3]. Formation of BUE may cause variation of cutting force, induce a shorter edge life, and lead to poor surface quality generation, due to the deteriorating effects of the torn material particles left on the chip [4]. A study on orthogonal cutting indicated that BUE affects chip formation and cutting ratio for different cutting conditions [5]. Another undesirable phenomenon in machining consists in burr formation, which comes from the projection of the material as a result of plastic flow from cutting and shearing operation [6]. Burr formation affects the final product and causes some critical problems such as surface finishing deterioration, reduced dimensional accuracy, prevent easy parts assembly and reducing part durability [7][8]. In micro machining burr reduction methods mainly consists in applying different machining strategies because many deburring methods, utilized in macro scale machining cannot be applied at the micro scale [9].

The micro burr formation was investigated in the past decades by exploiting mainly experimental, analytical and numerical methods. In particular, different studies classified burrs formation according to its location in milling process i.e. entrance burr, exit burr, side burr, top burr and bottom burr [8] [10]. Biermann and Steiner [11] investigated burr formation in micro milling of austenitic stainless steel with different cutting conditions, tool type and lubrication methods in order to consider dissimilar variables on the top burr formation.

Micro machining simulations have become a powerful method to predict cutting information prior to machining [12]. It rapidly expanded within last decades due to its benefits and the development of powerful computers. The finite element technique demonstrates to produce detailed information on the cutting process phenomena [13] [14]. Finite element analyses can provide information on the metal cutting process that is impossible or difficult to obtain with experimental or analytical methods.

Several studies performed numerical simulation to investigate the effects of burr formation in normal cutting conditions. Park and Dornfeld developed 2D finite element models to study influence of various process parameters for better understanding the burr formation mechanism [15]. The same authors studied the exit burr formation of various workpiece exit edge angles from $60^{\circ}$ to $120^{\circ}$ for the case of orthogonal cutting. It is observed that the use of larger tool rake angles can also reduce the burrs [16]. In another study 2D FE model of orthogonal metal cutting was developed to investigate quantitative analysis of burr or breakout formation on the exit burr [17].

The 3D FEM simulations present supplementary analysis capabilities to investigate the effect of helix angle and tool edge radius, on chip flow and burr formation, which cannot be investigated by 2D FEM [18]. However, very few researches investigated micro milling by means of 3D FE simulations making use of its distinct advantages. Yang et al. [19] established 3D FEM in micro end-milling of A12024-T6 to predict the effect of various tool edge radiuses and tool tip breakage on the burr formation. Significant effect of the tool edge radius on the top burr formation was observed. Another study focused on the burr formation prediction capability of 3D FEM in micro ball milling of Ti-6Al-4V alloy [20] in which the correlation between cutting parameters and top burr size was investigated. In a recent study, 3D FEM simulations were used to predict chip flow and shape during Ti-6Al-4V alloy micro end-milling. The FEM considered the wear along the micro tool by investigating the influence of the cutting edge roundness increment on the machining process performance without considering the burr formation [21].

Most of the previous studies in scientific literatures deal with the effect of cutting parameters on the different types of chip flow and burrs generation in ideal tool conditions. Some papers have investigated 2D FEM that deals with burr formation [15] [16] [17] and even less publications on 3D FEM [19] [20] that directly address and explain the specific cutting problems such as (BUE) influence on the cutting process.

In the present study, 3D FE simulations of micro end-milling is carried out on Aluminum Al6082-T6, by considering the exact tool geometry to investigate the burr formation capability of the model in different cutting conditions. The 3D FE model first implemented with the actual tool geometry CAD model and then with the CAD model of the tool affected by built up material, attached to the tool from the workpiece during machining. The results of FE models were finally compared in order to highlight the differences in both models and differences in burr, chip formations and cutting forces.

\section{3D Finite element modeling}

A 3D micro end-milling model for A16082-T6 alloy is developed using an explicit time integration method and employing a Lagrangian finite element formulation to perform a coupled thermo-mechanical transient analysis. The AdvantEdge ${ }^{\circledR}$ FEM software (by Third Wave Systems) is used to construct FE model. FEM prediction can be strongly influenced by the specific software adopted and so its adequate selection is an important part to obtain reliable results [22] [23]. In the study, simulations are performed on a computing server equipped with a processor characterized by 2.6 GHz and 16 cores, 64 GB RAM. 8 threads parallel simulation mode is used to speed up the calculation time of about six times. The calculation time was in the range between 30 and 90 hours depending on the considered cutting condition.

The influence of tool geometry on the chip formation, cutting temperature, and tool wear was demonstrated in recent research works [24][25] [26]. In the present study, the micro end-mill is modeled in two different conditions. First, a CAD model is generated starting from the actual tool geometry (Table 3) measured prior to machining. Then, a second CAD model is generated after machining passes taking into account the adhered material which constitutes the cutting tool BUE. The actual characteristic of the tool was acquired by a Focus variation 3D optical measuring system (Alicona Infinite Focus $($ ). A preliminary cutter cloud of points is generated and used to precisely describe the geometry of the tool. Fig. 1 shows the 3D CAD models of actual tool geometry of the micro end-mill with and without BUE. The cutting tool angles significantly affect the 
machining processes, and by forming the BUE on the cutting edges, the active part of the cutting edge increases. It is mainly influenced the rake face angle, flute angle, relief angle, cutting edge radius $\left(r_{\mathrm{e}}\right)$ and corner radius $\left(r_{\varepsilon}\right)$ as shown in Fig. 1(b). The tool with BUE is modeled according to the tool used in the experiment (Fig. 4(c)). Energy dispersive X-Ray (EDX) analyses were carried out on the various points of the tool tip in order to declare the adhered material was A16082. Only a small portion of the tool tip is simulated in order to decrease simulation time.

Fig. 2 shows the setup, boundary conditions and general geometry of the 3D FEM simulation in both full slot micro end-milling and contour up milling. The workpiece boundary nodes are fixed in $X Y$ and $Z$ bottom directions and the tool is constrained in $Z$ top direction. Feed is applied by moving the tool along the $X$ direction.

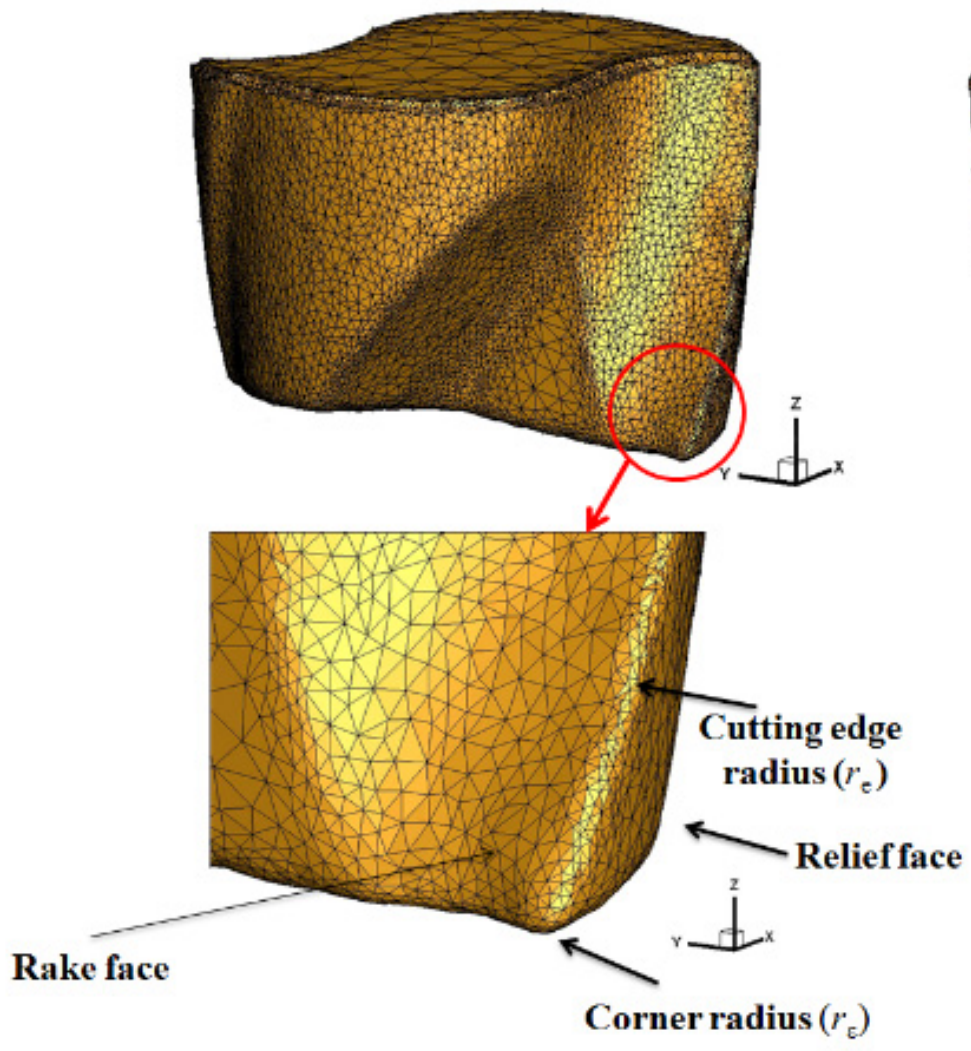

(a) Fresh tool

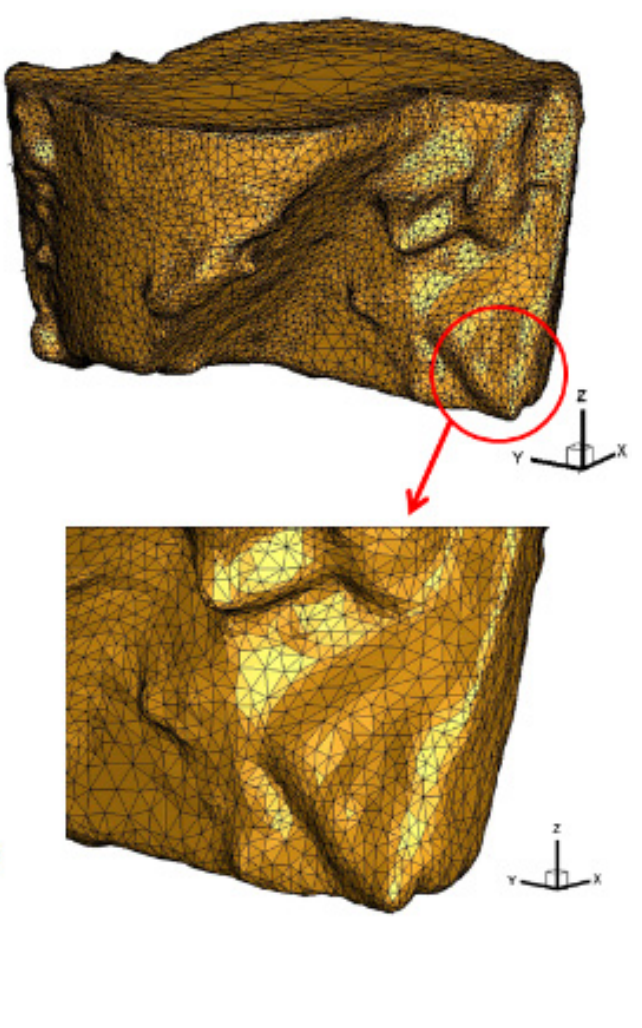

(b) Tool with BUE

Fig. 1: 3D CAD models of (a) actual tool geometry (b) tool with BUE

Tool and workpiece are kept at their ideal dimensions during the simulation to maintain steady state cutting conditions and save simulation time. The cutting tool is considered as a rigid body and workpiece is considered constituted by viscoplastic material. The meshing method includes a set of boundary, dimensional, parametric and adaptive criteria [27].

Tool and workpiece are remeshed with the 4-node tetrahedral element types available in the software. The details of the meshing parameters are summarized in Table 1. The parameters are selected after preliminary evaluation tests performed in previous studies [14] [23]. A higher mesh density is considered in the area where chip is expected to form, i.e. near the cutting zone and tool cutting edge radius (Fig.1 (a)), in order to increase the accuracy of computed outputs. Adaptive remeshing is applied in order to avoid the inaccuracies due to elemental distortion, inherent to the Lagragian formulation. The mesh quality is constantly monitored during the simulations and when the element distortion reaches a certain tolerance, adaptive remeshing is triggered. In addition to remeshing, refinement and coarsening operators are applied in various parts of the mesh. The mesh is refined where the plastic deformation is active and coarsened in inactive regions [28]. The adaptive remeshing parameter for minimum element edge length of the chip bulk is set to $3 \mu \mathrm{m}$ and the minimum element on the cutter is set to $2 \mu \mathrm{m}$.

The friction phenomenon at the chip-tool interface is modeled using the Coulomb friction, as shown in Eq. (1). The frictional stresses $\tau$ on the tool rake face are assumed to be proportional to the normal stresses $\sigma_{n}$ with a coefficient of friction $\mu$. According to Özel [29] the sliding friction can be dominant during the low cutting speed machining and the sticking friction is dominant during the high-speed machining. In micro milling although, using high rotational speed but due to the small diameter of the tool, the cutting speed stay lower than in the macro scale milling process (in this study a cutting speed $31 \mathrm{~m} / \mathrm{min}$ was employed). Consequently, the Coulomb sliding friction model is effective in the micro milling process. A constant value of friction coefficient used is assigned in this study, as $\mu=0.7$. This value is selected basing on previous experimental identification made by Medaska on Al6061-T6 with carbide tools [30]. 

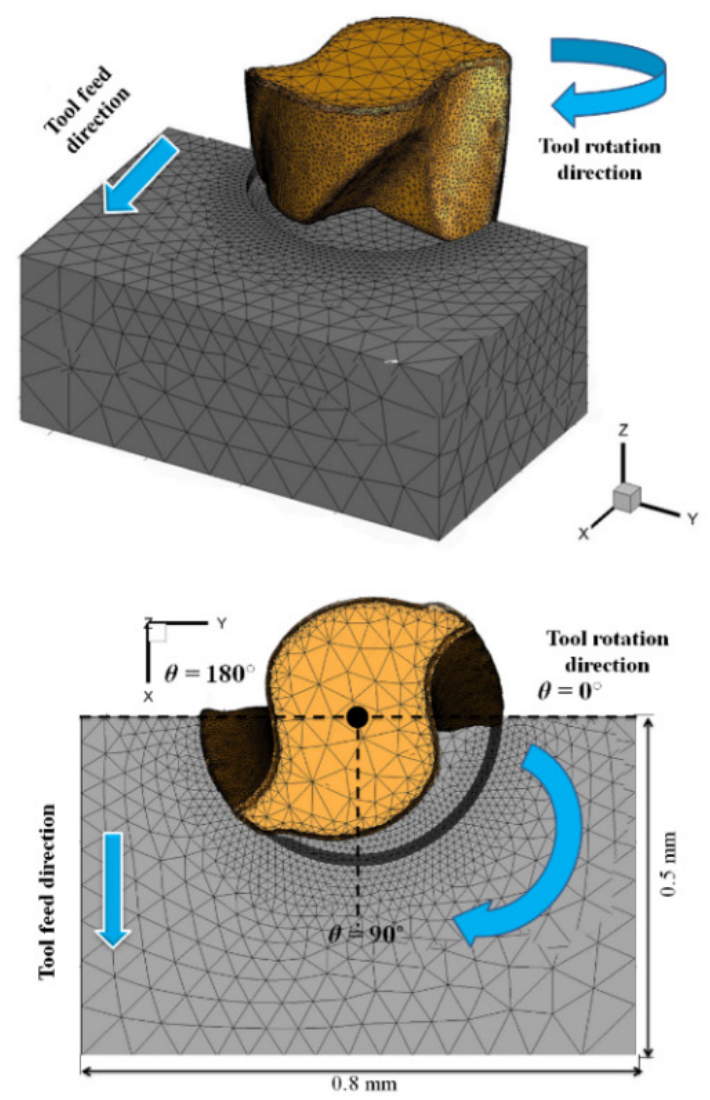

(a)

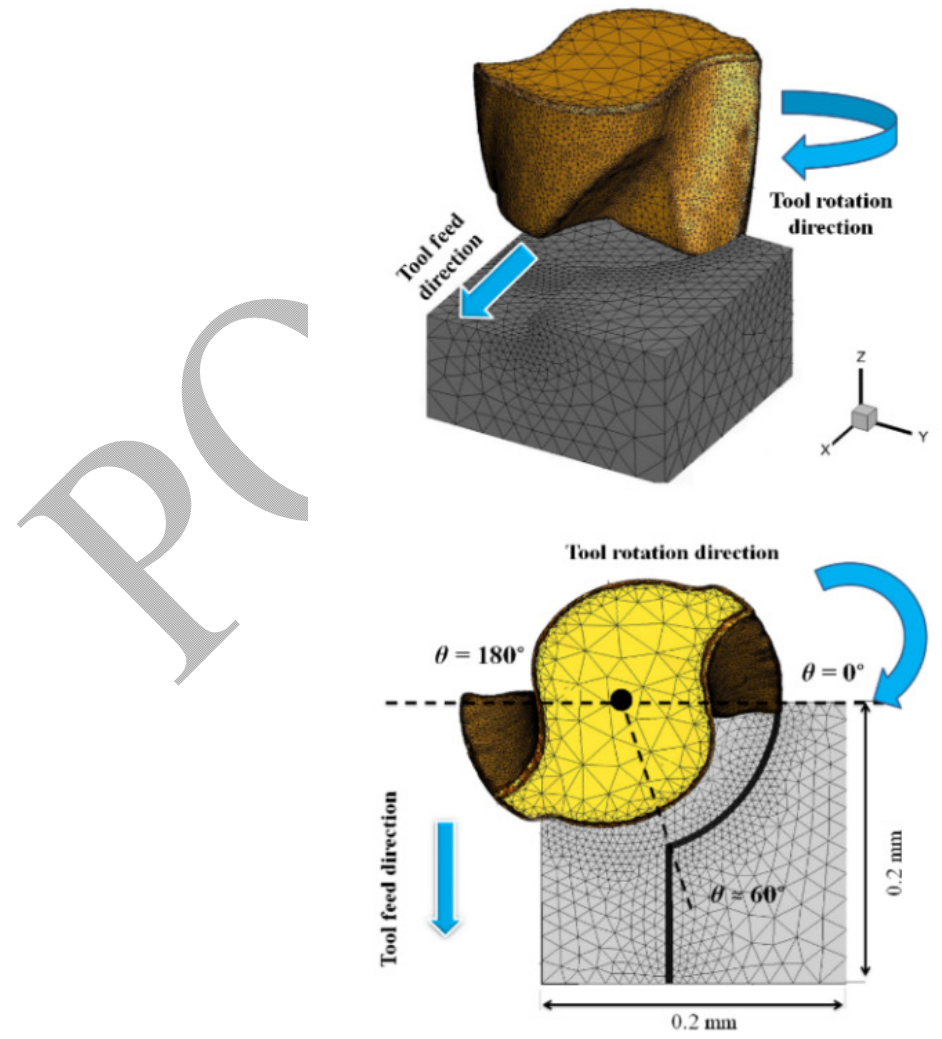

(b)

Fig. 2: 3D FE model for (a) full slot and (b) contour up micro end-milling 
A16082-T6 and Al6061-T6 are two popular aluminum alloys where sometimes replacing each other in the industrial practice due to the similar characteristics.

$$
\tau=\mu \sigma_{n}
$$

Table 1: Meshing parameters

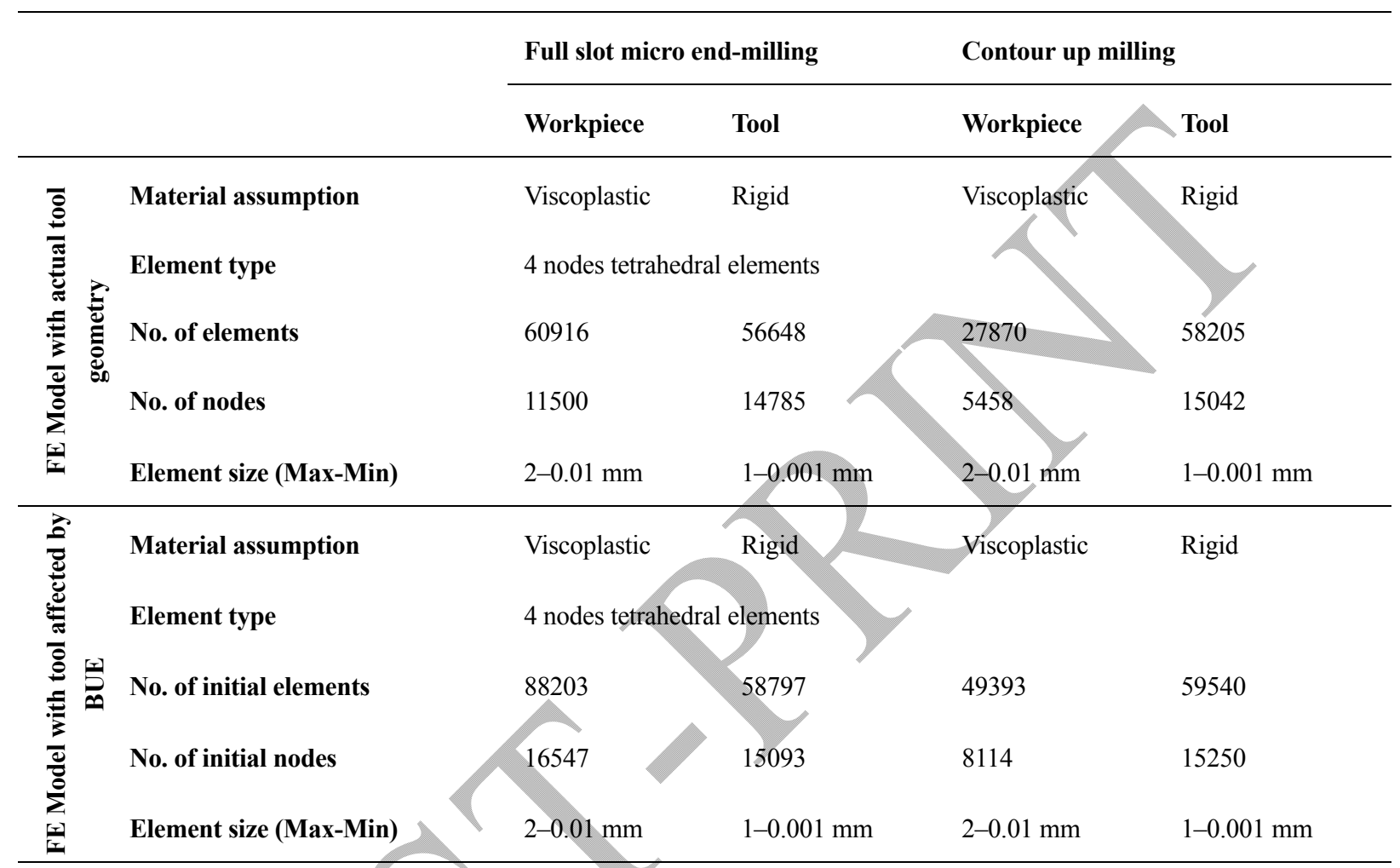

On the other side, the workpiece is modeled by using the Johnson-Cook (JC) constitutive equation (Eq. 2) [31]. The model is a strain rate and temperature dependent visco-plastic material model, widely accepted in the machining simulation field.

$$
\sigma=\left(\mathrm{A}+\mathrm{B}(\varepsilon)^{\mathrm{n}}\right)\left[1+\mathrm{C} \ln \left(\frac{\varepsilon^{\prime}}{\varepsilon_{0}^{\prime}}\right)\right]\left[1-\left(\frac{T-T_{a}}{T_{m}-T_{a}}\right)^{m}\right]
$$

Where $\sigma$ is material flow stress, $\varepsilon$ is plastic strain, $\varepsilon^{\cdot}$ is the strain rate, $\varepsilon_{0}^{\cdot}$ is reference strain rate. $T$ is material temperature, $T_{m}$ is the melting point and $T_{a}$ is the room temperature. The JC constants are as follows: $A$ is the yield stress, $B$ is the pre exponential factor, $C$

is the strain rate factor, $n$ is the work hardening exponent and $\mathrm{m}$ is the thermal softening exponent. The constants used in the 3D FE model for Al6082-T6 are listed in Table 2 and the physical properties are presented in Table 2. The constants $\left(B, C, M, T_{\mathrm{m}}\right)$ adopted from [32] and constants ( $A$ and $n$ ) are modified base on the inverse method analyses on experimental cutting forces conducted in [33].

\section{Experimental procedure}

Micro milling operations are performed on a Kern EVO ultra precision 5-axis machining center with nominal positioning tolerance $= \pm 1 \mu \mathrm{m}$, precision on the workpiece $= \pm 2 \mu \mathrm{m}$, as declared by the manufacturer. The machine tool and experimental setup are illustrated in Fig. 3. The cutting tool selected was a micro flat end mill Dormer S150.05 with surface treatment of TiAlN-X (Titanium Aluminum Nitride Extreme). Table 3 shows the characteristics of the actual tool geometry and tool affected by BUE. The tools are inspected and measured by a 3D optical measuring system (Alicona Infinite Focus $($ ) prior to the machining (measurement parameters: 10x magnification, exposure time $=1.206 \mathrm{~ms}$, contrast $=1$, coaxial light, estimated vertical and lateral resolutions $=0.083 \mu \mathrm{m}$ and $4 \mu \mathrm{m}$ ). 
Table 2: Material properties and the JC model constants for Al6082- T6

\begin{tabular}{lll}
\hline Property & & \\
\hline Young's modulus E & $(\mathrm{GPa})$ & 70 \\
Poisson ratio $v$ & ----- & 0.33 \\
Density $\rho$ & $\left(\mathrm{g} / \mathrm{cm}^{2}\right)$ & 2.70 \\
Thermal conductivity K & $\left(\mathrm{W} / \mathrm{m}^{\circ} \mathrm{K}\right)$ & 180 \\
Specific heat $C p$ & $\left(\mathrm{~J} / \mathrm{Kg}{ }^{\circ} \mathrm{C}\right)$ & 700 \\
Thermal expansion coefficient & $\left({ }^{\circ} \mathrm{C}\right)$ & $24 \times 10^{-6}$ \\
\hline Material constants for the JC model & & \\
\hline A & $(\mathrm{MPa})$ & 214.25 \\
$\mathrm{~B}$ & $(\mathrm{MPa})$ & 327.7 \\
$\mathrm{C}$ & & 0.00742 \\
$\mathrm{M}$ & & 1.3 \\
$\mathrm{~N}$ & & 0.504 \\
$T_{\mathrm{m}}$ & $\left({ }^{\circ} \mathrm{C}\right)$ & 582 \\
$T_{\mathrm{a}}$ & $\left({ }^{\circ} \mathrm{C}\right)$ & 21 \\
\hline & &
\end{tabular}

The cutting tool tips are inspected and measured prior to the machining and the tools with minimal geometrical deviation and defect are selected for the experiments. Micro end-mill are held in tool holders KERN/SCHAUBLIN HSK32 and a precise SCHAUBLIN collet type D14 (74-14000) is used in order reduce the clamping error and the overall tool run-out. The series of micro milling experiments on Al6082-T6 are carried out in different cutting conditions as shown in Table 3. The experimental plan was considered as a $2^{2}$ full factorial design of experiments. Four cutting conditions replicated four times. The cutting parameters, in particular the two different feed per tooth $\left(f_{z}\right)$, and the radial depth of cut $\left(a_{\mathrm{e}}\right)$ are selected in order to limit the contact area around the cutting edge radius to include the unavoidable minimum chip thickness effect. The up milling approach is selected to maximize the same effect. Each cutting condition is replicated four times to guarantee statistical consistency, hence the whole experimental design consisted of 16 tests. The same mill is used to carry out the entire experiments. The machining surfaces are prepared rigorously prior to the final tests in order to have perfect condition in dry micro milling. Fig. 4 shows SEM picture of the fresh and used tool with different machining lengths in the experiments with cutting edge magnification. Additionally Energy-dispersive X-ray spectroscopy (EDX) analysis carried out in order to find out the particular elements on the cutting edge. The inspection field within which the EDX data were collected by rastering the incident electron beam to produce the spectrum is shown in Fig. 4 magnified images and marked with green A. The tabulated results provide main detected elements in the inspection field in units of weight percent. The micro slots were acquired by SEM and 3D optical microscope (Alicona Infinite Focus with measurement parameters: 10x magnification, exposure time $=110 \mathrm{~ms}$, contrast $=1$, coaxial light, estimated vertical and lateral resolutions $=3.6 \mu \mathrm{m}$ and $2.4 \mu \mathrm{m}$ ). Concerning the burr shape and height different measurements of the slot are taken with various axial steps as shown in Fig. 5.

The workpiece in a cylindrical form is fixed on a miniature piezoelectric three axial dynamometer Kistler 9317B which cutting force signal have been measured (measuring range: $F_{\mathrm{x}}, F_{\mathrm{y}}= \pm 1 \mathrm{kN}, F_{\mathrm{z}}= \pm 2 \mathrm{kN}$; linearity error $\leq 0.5 \% \mathrm{FSO}$, Full Scale Output) amplified by three Kistler 5015A charge amplifiers (Fig. 3(b)). A low-pass filter at $20 \mathrm{KHz}$ is applied directly on the charge amplifiers in order to avoid aliasing. The acquisition length is one second for each milling step. Due to the low resonance frequency of the fixturing and force measurement system, cutting force measurements results were affected by vibrations. Thus, in order to accurately measure the micro milling forces an inverse dynamic model is adopted as compensation method. Model parameters of the dynamometer (with the workpiece used in tests installed on it) are identified by performing impact testing on both $X$ and $Y$ directions.

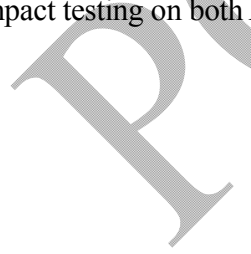




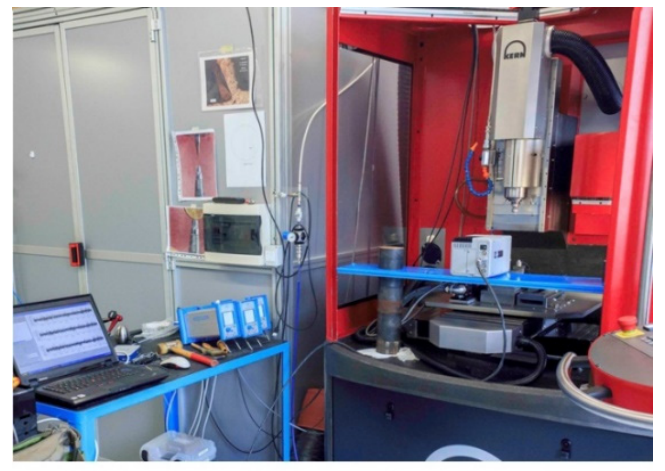

(a)

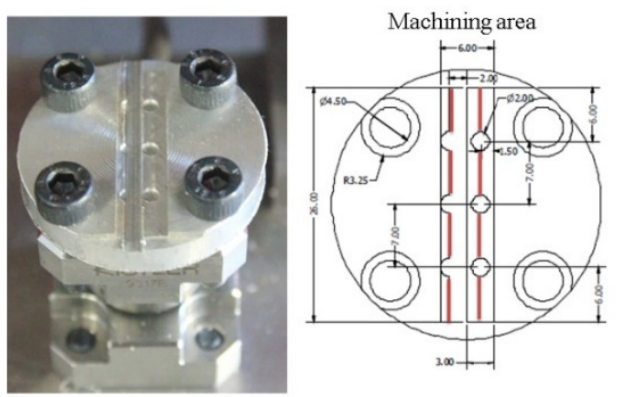

(b)

Fig. 3(a): Setup for micro milling tests (b) workpiece and machining area

Table 3: Characteristic of the micro end-mill and experimental conditions

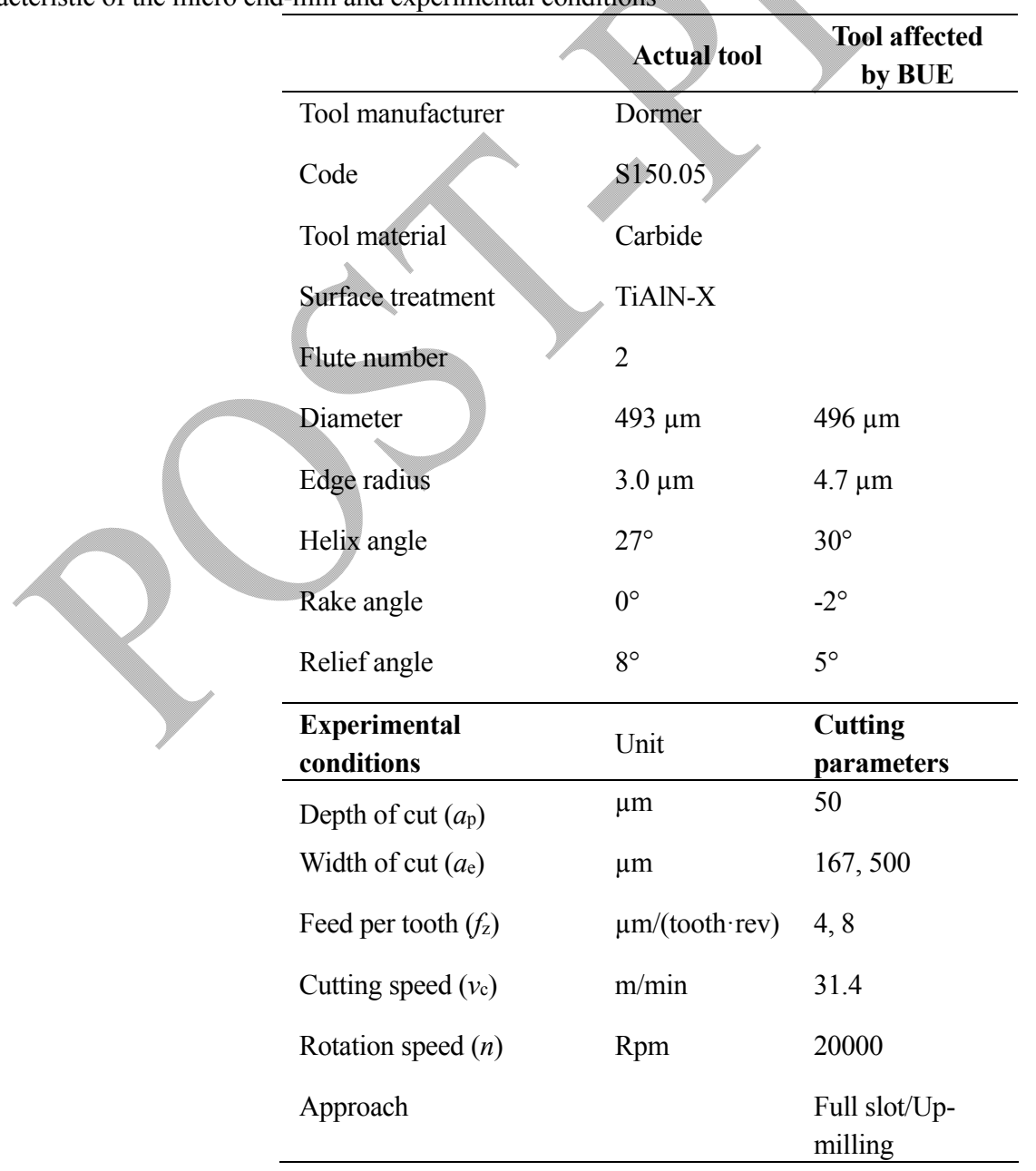




\section{Results and discussion}

In this section, a comparison between FEM with actual tool geometry, tool affected by BUE and experimental results is performed to enhance the understanding of the chip and burr formation. Full slot and contouring micro end-milling simulations are carried out for booth teeth engagements $360^{\circ}$ tool rotation.

\subsection{Chip formation}

Fig. 6 shows comparison of chips obtained in numerical results with actual tool geometry and tool affected by BUE in full slot micro endmilling and contour up milling, respectively. The result of the chip formation presents varies chip shape in the same angular engagement. The BUE altered the geometry of the tool, consequently the material removal and chip formation changed. The bigger cutting edge radius ( $\mathrm{r}_{\mathrm{e}}$ ), corner radius $\left(\mathrm{r}_{\varepsilon}\right)$ and negative rake angle $(\alpha)$ involved in the cutting and then ploughing become dominant. The importance of the cutting edge geometry effect on micro milling process is confirmed by previous studies. In particular, they studied its impact on: cutting forces [34], ratio of undeformed chip thickness [35], quality of machined surface [2].

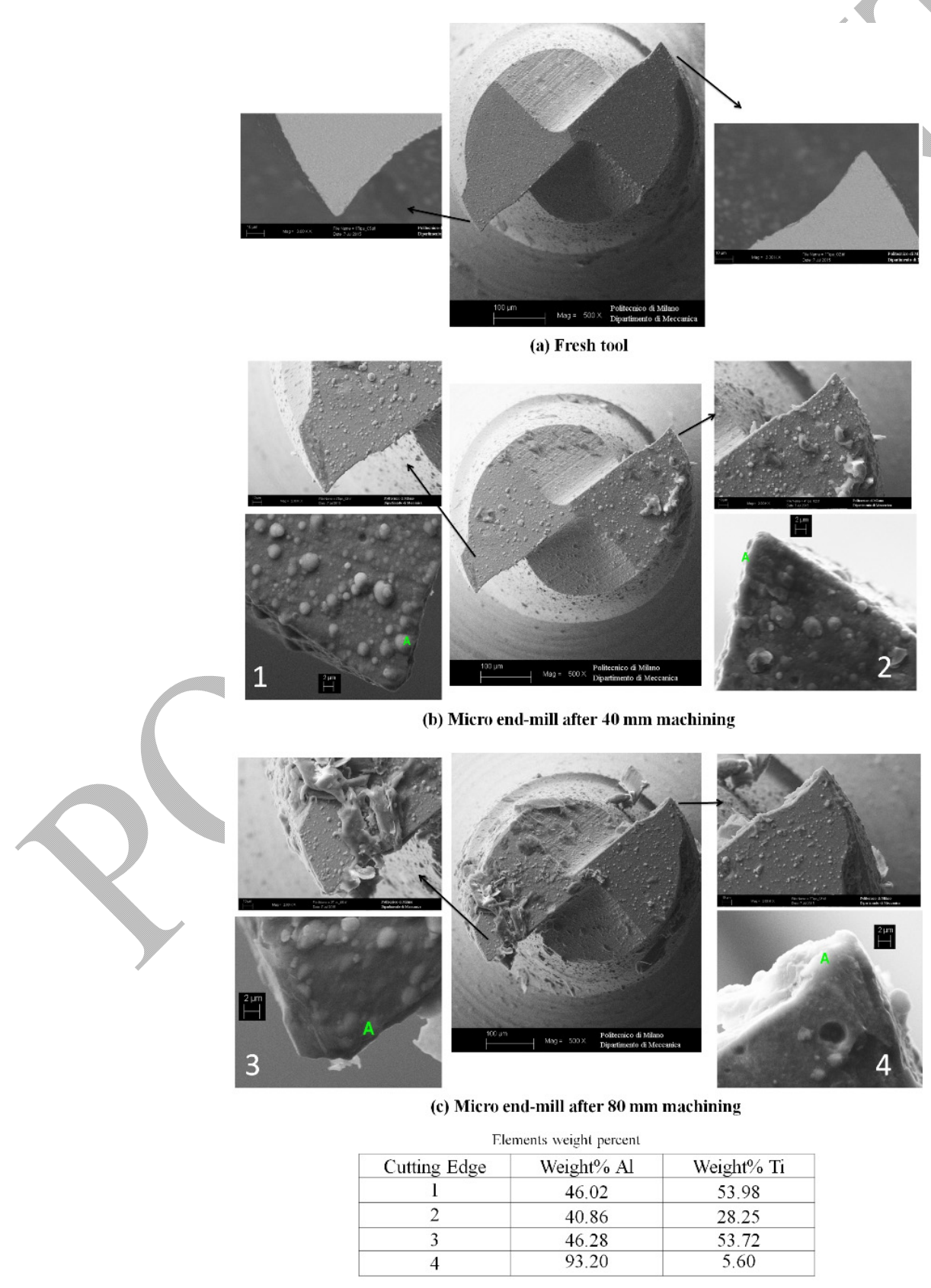

Fig. 4: SEM images of micro end-mill and tool tip: (a) fresh tool (b) - (c) used tool 


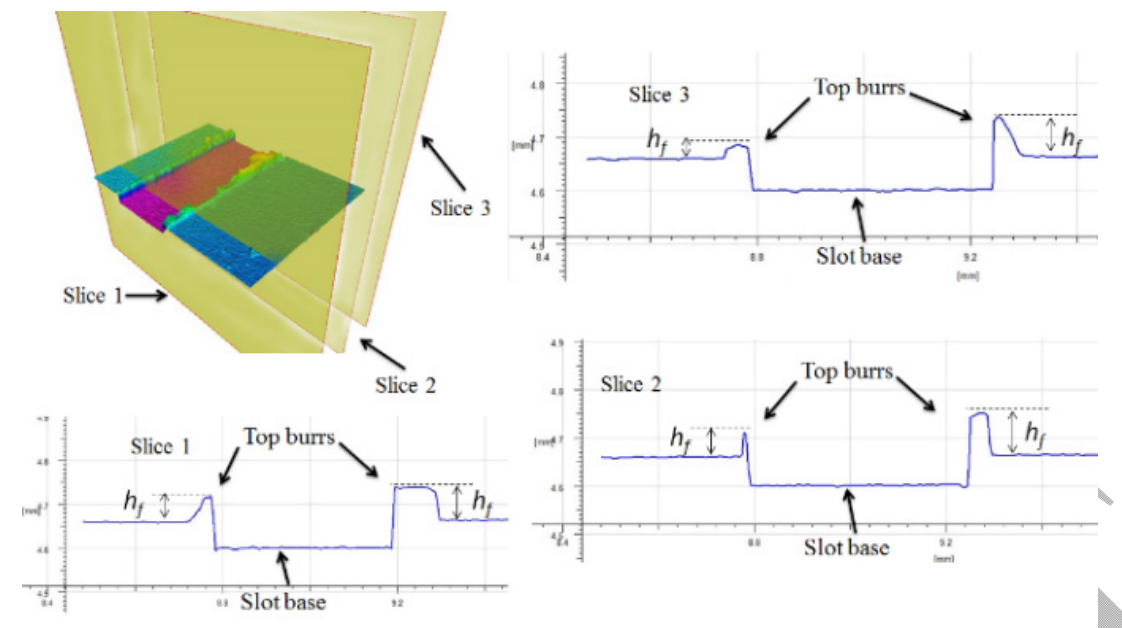

Fig. 5: Characterization of the micro slot burr height and geometry

The simulation results show for the tool affected by BUE unequal chip load and formation were obtained in the engagements. Fig. 7 illustrates the simulated chip morphology at the end of cut and compared with experimental chips in different cutting conditions. The simulated chips with the tool affected by BUE have different form and shape. Some additional workpiece material particles on the shape of the chips profile were observed in comparison to the chip shape simulated with actual tool geometry in all cutting conditions. However, it was more visible in the full micro end milling approach due to the more tool and workpiece interface engagement. This variation of the chips might be due to the blunt edges of the cutting tool that causes the ploughing effect in cutting process and chip formation. Additionally, due to the dissimilar cutting edge geometry in the first engagement greater material is removed. However, in the second engagement smaller portion of workpiece removed in comparison to the previous one.

\subsection{Burr formation}

The simulation results of the top burr are shown in Fig. 8, where top burr is formed on the top of the micro slot workpiece surface in full slot micro end-milling and contour up milling. In the cutting process, not all the deformed material forms the removed chip because part of it is transformed in burr formation. The influence of the tool affect by BUE on the burr generation is noticeable and creates larger burrs, as shown in Fig. 8 (b) in both full slot micro end-milling and contour up milling. It can be also noted that after the second tooth engagement the chip is not completely shaped and pushes the top burr area of the workpiece to form, without being detached. This phenomenon is equivalent with the experimental results on the top burr formation, as shown in Fig. 8(c) and Fig. 8(d) full slot milling. However, in the simulations that take into account the actual tool geometry, but not BUE, the chips are generated in both teeth engagements and leave the surface Fig. 8 (a). The results of the full slot milling process show that each side of the top burr generation is different (Fig. 8(b) and Fig. 8(c)). This occurs in full slot milling due to the different cutting approaches (up milling and down milling) in each side of the slot.

In the contour up milling the effect of BUE on the cutting is also visible (Fig. 8 (b)) and larger burrs are generated. However, in comparison to contour up milling process, it can be observed that larger top burrs are generated in full slot machining. The burr height predicted by the model is compared against the experiments in Fig. 9 in all cutting conditions. The simulation standard error was calculated based on the first and second tool engagements burr formation measurements.

Comparison of simulated burr height in full slot micro end-milling and contour up milling illustrated that, higher burr height was formed with the burr formation involves the tool affected by BUE than the fresh tool. It might be due to the blunt edges of the cutting tool, pushing more materials toward the workpiece than removing them, and causing higher burr on the machined wall, and worsen the surface finish of the machining. The highest burr height was observed at the severe cutting condition $\left(a_{\mathrm{e}}=500 \mu \mathrm{m}\right.$ and $f_{\mathrm{z}}=8 \mu \mathrm{m} /($ tooth $\left.\cdot \mathrm{rev})\right)$. A comparable result with the experiments is produced by the model that involves the tool affected by BUE than the other which considers the actual tool geometry. 

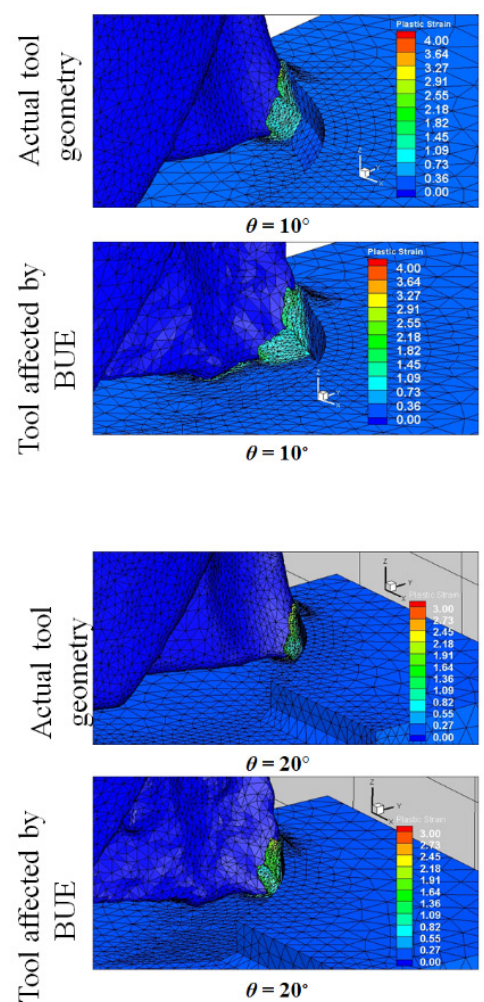

$\theta=20^{\circ}$

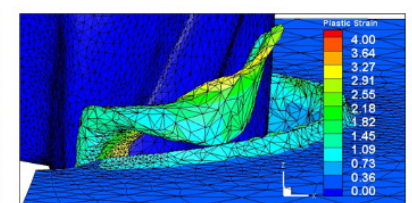

$\theta=160^{\circ}$

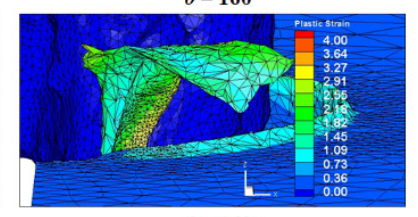

$\theta=160^{\circ}$

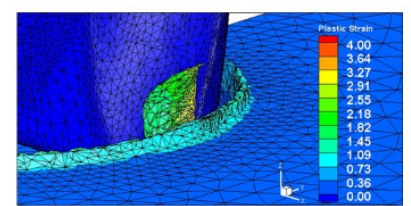

$\theta=\mathbf{2 6 0 ^ { \circ }}$

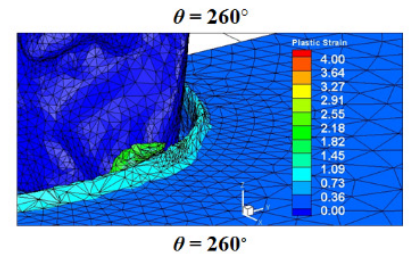

$\theta=260^{\circ}$
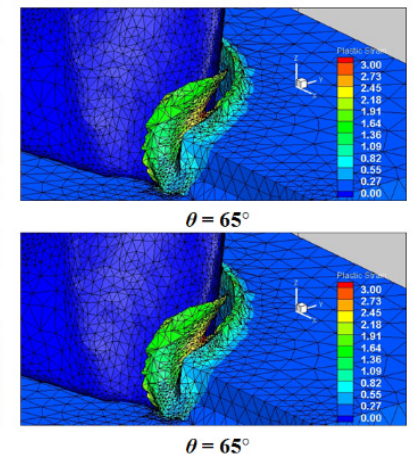

(b) Contour up milling

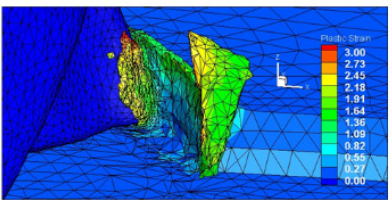

$\theta=\mathbf{2 1 0} 0^{\circ}$

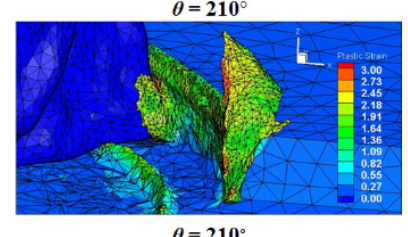

$\theta=\mathbf{2 1 0} 0^{\circ}$

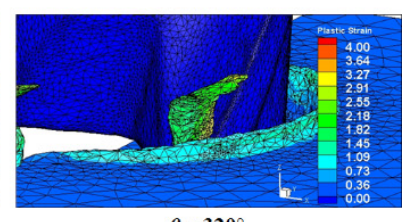

$\theta=320^{\circ}$

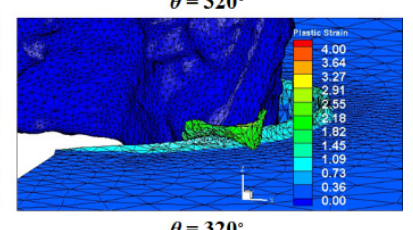

$\theta=320^{\circ}$
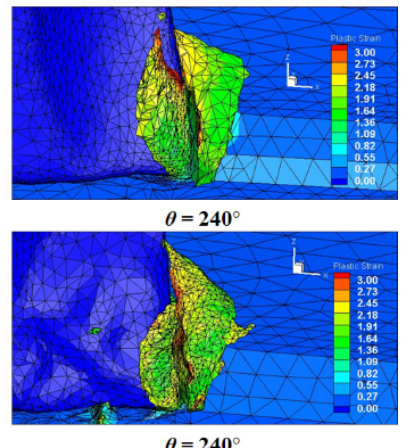

\section{Co}

Fig. 6: (a) Full slot micro end-milling (b) Contour up milling 3D chip formation and plastic strain distribution at different angular position at actual tool geometry and tool affected by BUE

In addition to the experimental and simulation results, design of experiments (DOE) analysis was carried out to illustrate the parameters contribution. Fig. 10 shows the interaction and main effect plots, All the simulations can predict correctly the influence of 'feed per tooth' and 'machining strategy' on the burr height following the same trends as in the experiments (Fig. 10(a)). Simulations including BUE are closer to the experimental results than the simulations without taking into account BUE. Average deviations depending on simulation type are $5.8 \mu \mathrm{m}$ without taking into account BUE $2.6 \mu \mathrm{m}$ taking into account BUE (Fig. 10(d)). Average \% deviations depending on simulation type are $19.9 \% \mu \mathrm{m}$ without taking into account BUE formulas $7.3 \% \mu \mathrm{m}$ taking into account BUE (Fig. 10(c)). Simulations are performing equally in terms of accuracy with respect to experimental results of burr height when simulating 4 or $8 \mu \mathrm{m} /($ tooth $\cdot$ rev) feed per tooth. In the range of 5-6 $\mu \mathrm{m}$ burr height deviation without taking into account BUE and in the range of 2-3 $\mu \mathrm{m}$ burr height deviation taking into account BUE. It was observed that simulations were less accurate with respect to experimental results of burr height when simulating full slot milling rather than simulating contour up milling. Without taking into account BUE: full slot milling $=9 \mu \mathrm{m}$ burr height deviation and contour up milling $=3 \mu \mathrm{m}$ burr height deviation however, by taking into account BUE: full slot milling $=5 \mu \mathrm{m}$ burr height deviation and contour up milling $=1 \mu \mathrm{m}$ burr height deviation (Fig. 10(b)).

\subsection{Cutting forces}

The comparison between simulated and experimental cutting forces is showed in Fig. 11 which depicts the three force components $F_{\mathrm{x}}, F_{\mathrm{y}}$, and $F_{\mathrm{z}}$ obtained for three rotations of cutting tool in full slot micro end-milling process. The comparison between simulated results of actual tool geometry and the one affected by BUE reveals dissimilar curve shapes and magnitude for different forces components. In the predicted forces with the actual tool geometry Fig. 11(a), similar trends are obtained in various teeth engagements. However, in another simulation influenced by the BUE, as showed in Fig. 11(b), different cutting force profile for each tooth engagement are produced. The cutting forces components increase in the first tooth engagement and decrease in the second one due to the effect of the BUE on the cutting edge roundness and geometry. Due to the small diameter of micro end-mill, the increase of the cutting force in one tooth engagements can increase the risks of developing tool breakage and damages of the machined area. Comparable experimental results in terms of curve shapes, Fig. 11(c), are obtained with FE simulated forces affected by BUE, especially for the two main force contributions $F_{\mathrm{x}}$, and $F_{\mathrm{y}}$. 

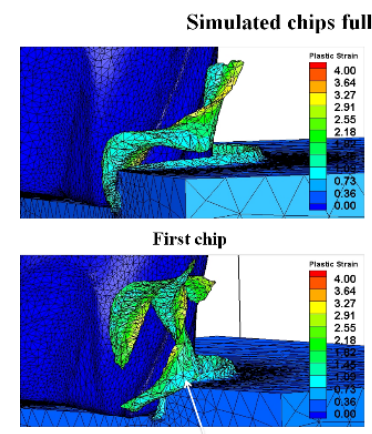

Second chip

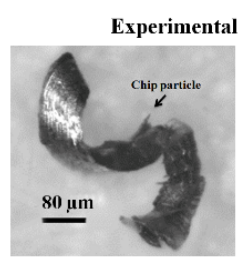

Second chip
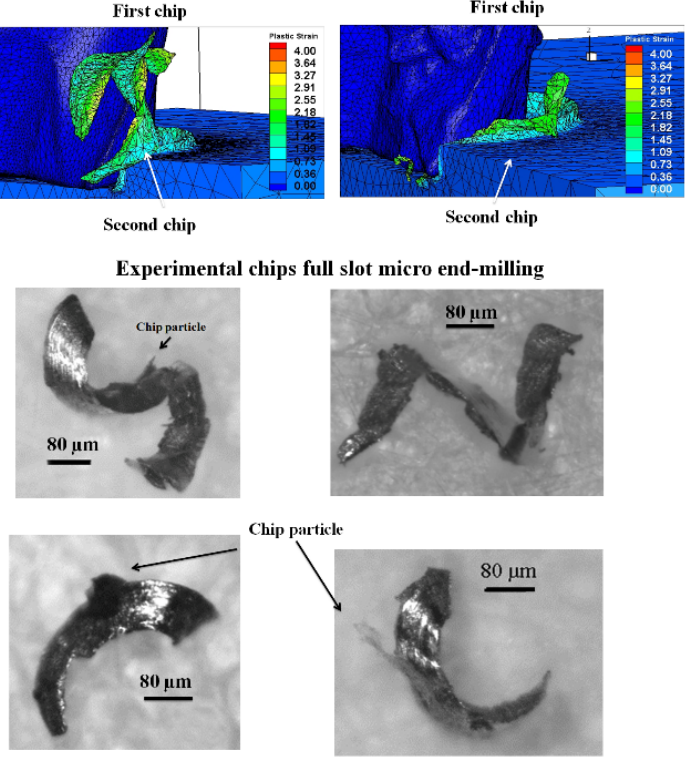
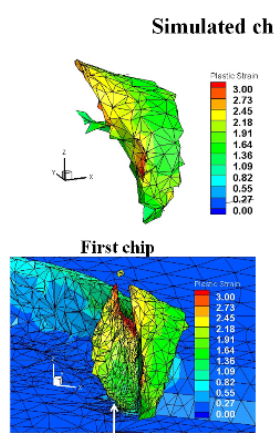

Second chip
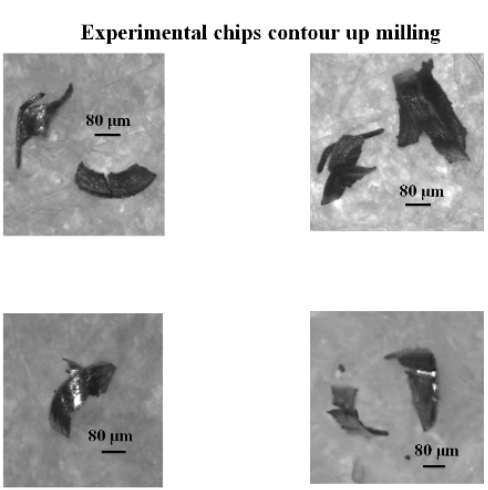

(a) Simulated and experimental chips at $f_{\mathrm{z}}=8 \mu \mathrm{m} /($ tooth $\cdot r e v)$

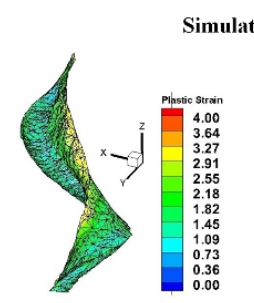

First chip

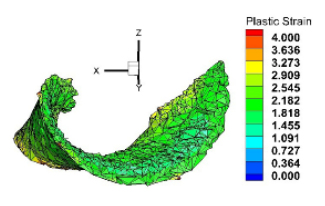

Second chip

Experimental chips full slot micro end-milling
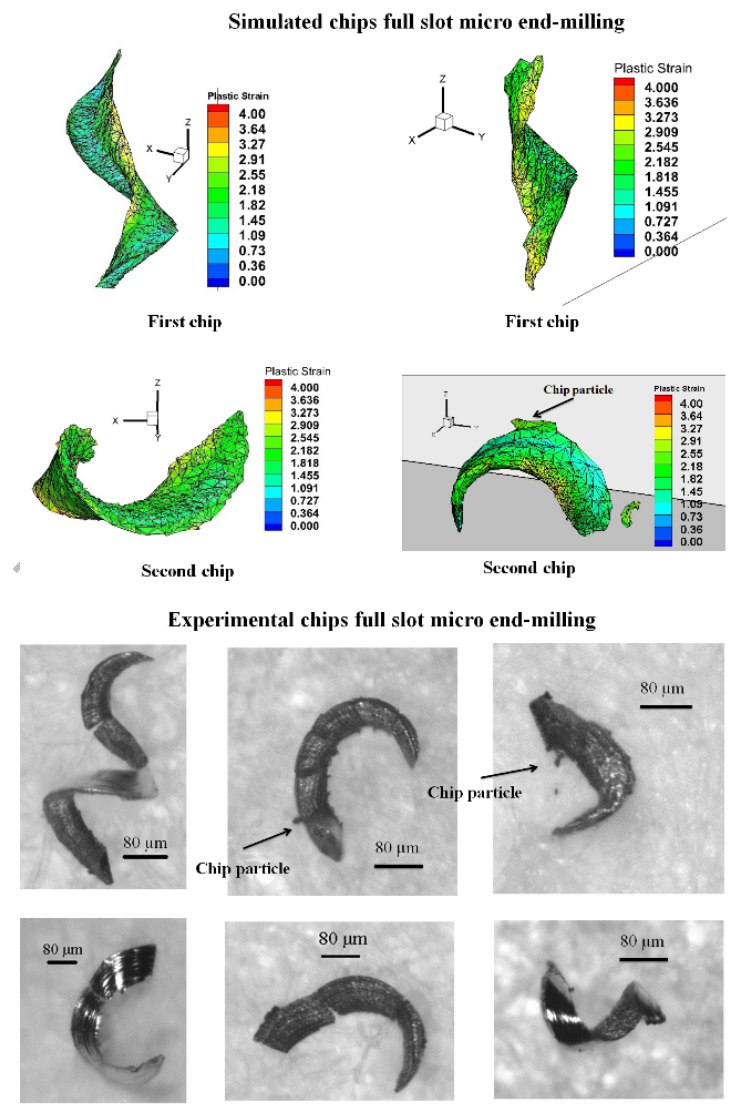

Second chip
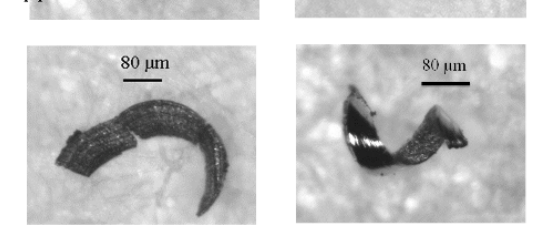

(b) Simulated and experimental chips at $f_{\mathrm{z}}=4 \mu \mathrm{m} /($ tooth $\cdot \mathrm{rev}$ )

Fig. 7 Full slot micro end-milling and contour up milling Simulated and experimental chips (a) at $f_{z}=8 \mu \mathrm{m} /\left(\right.$ tooth $\cdot$ rev) and (b) $f_{z}=4 \mu \mathrm{m} /($ tooth $\cdot$ rev) 

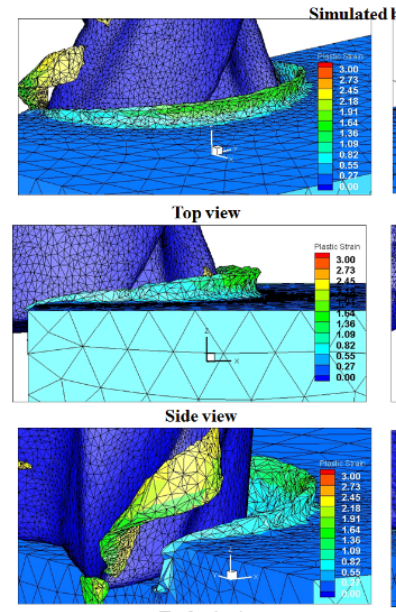

Tool exit view

(a)

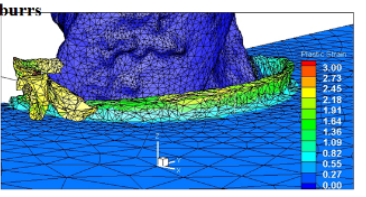

Top view

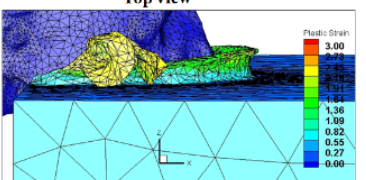

Side view

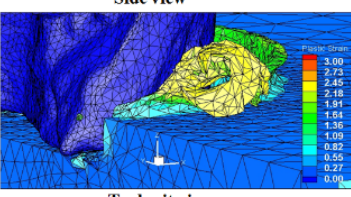

ool exit vie

(b)

Experimental burrs (3D microscope)

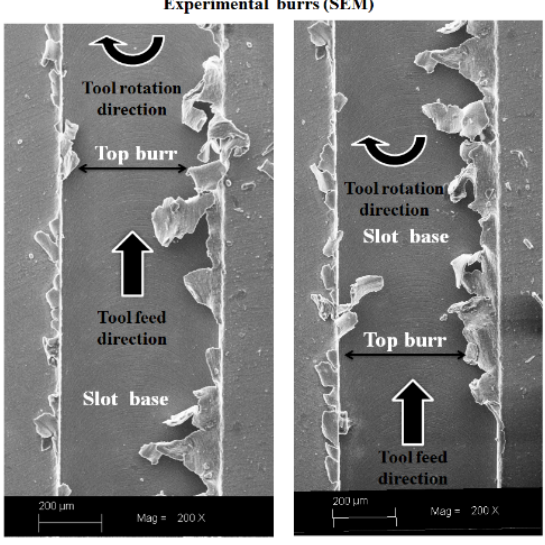

(c)

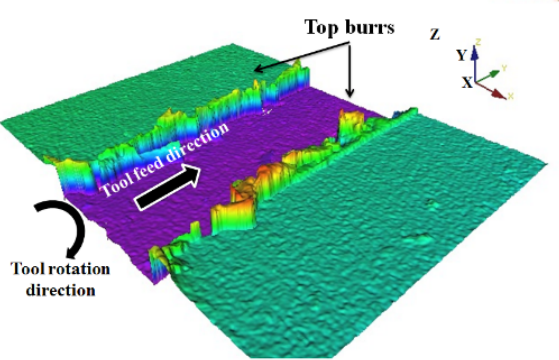

(d)

Full slot micro end-milling

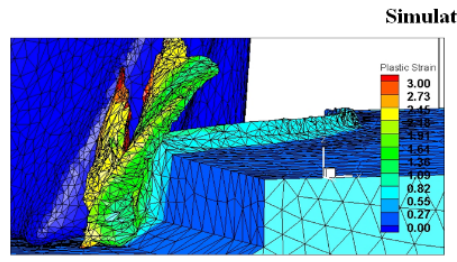

Side view

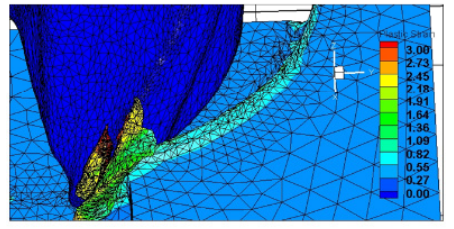

Top view

(a)

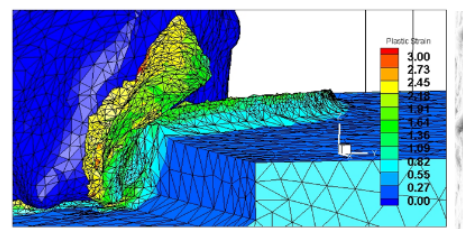

Side view

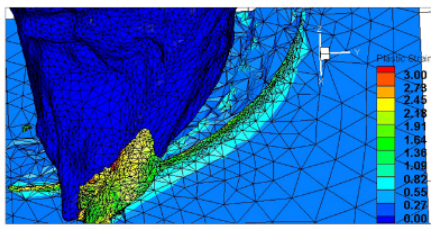

Top view

(b)

Experimental burrs (3D microscope)
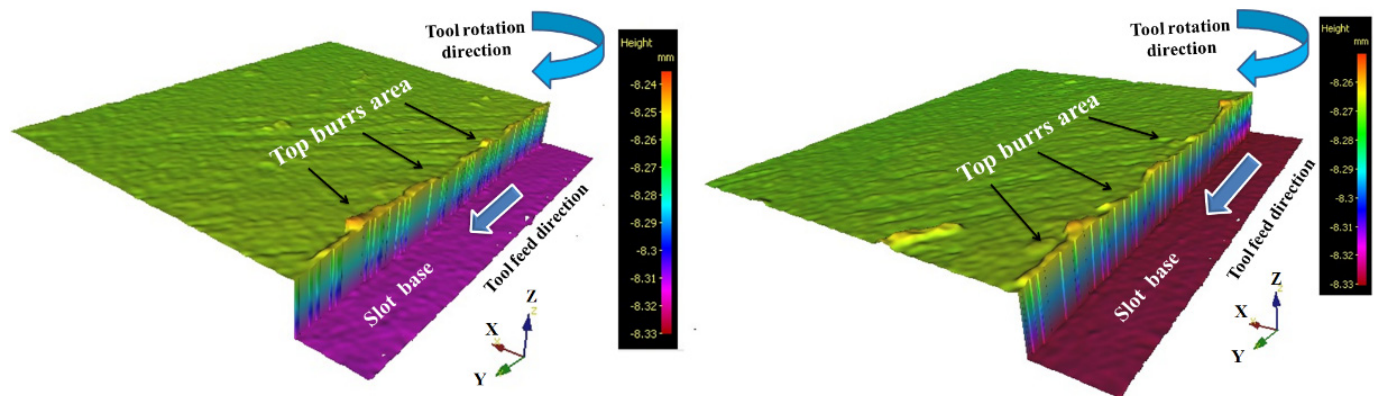

(d)

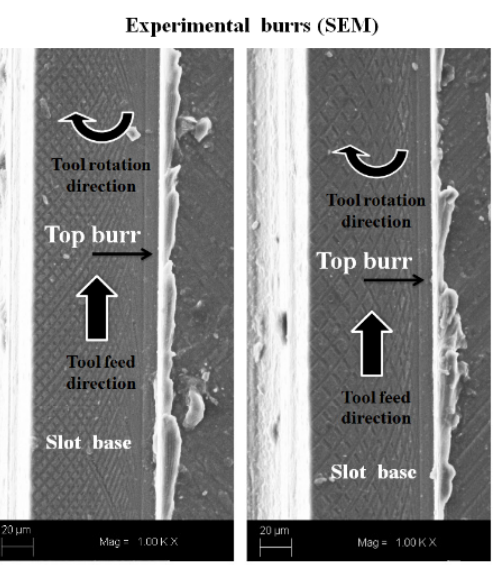

(c)

\section{Contour up milling}

Fig. 8: Full slot micro end-milling and contour up milling burr formation at $f_{\mathrm{z}}=8 \mu \mathrm{m} /($ tooth $\cdot$ rev) (a) actual tool geometry (b) tool affected by BUE simulations (c) SEM image of experiment (d) 3D microscope experiments burr height 


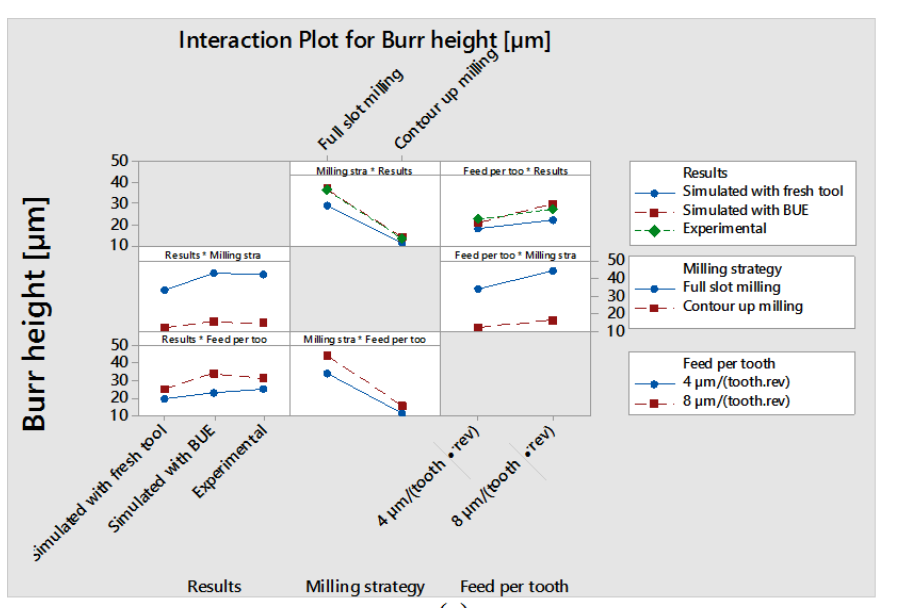

(a)

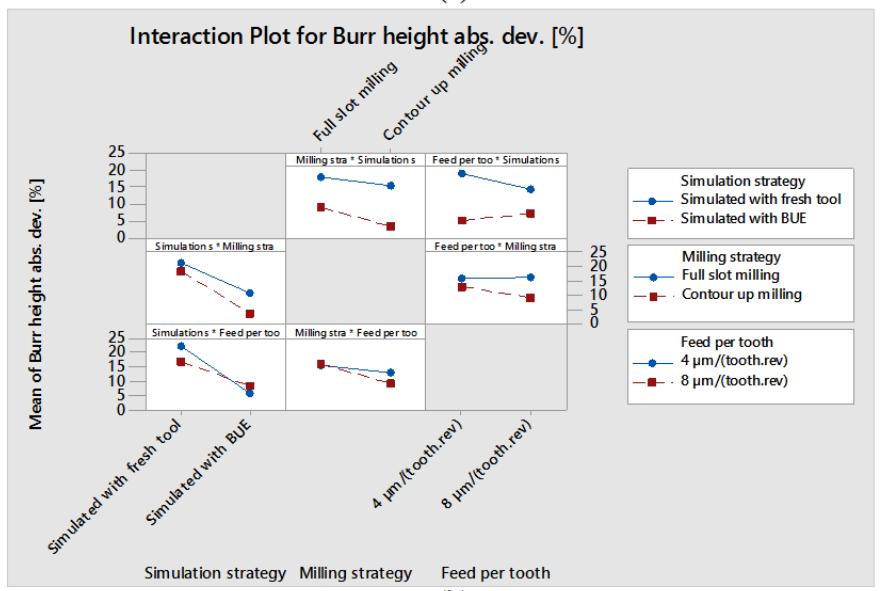

(b)

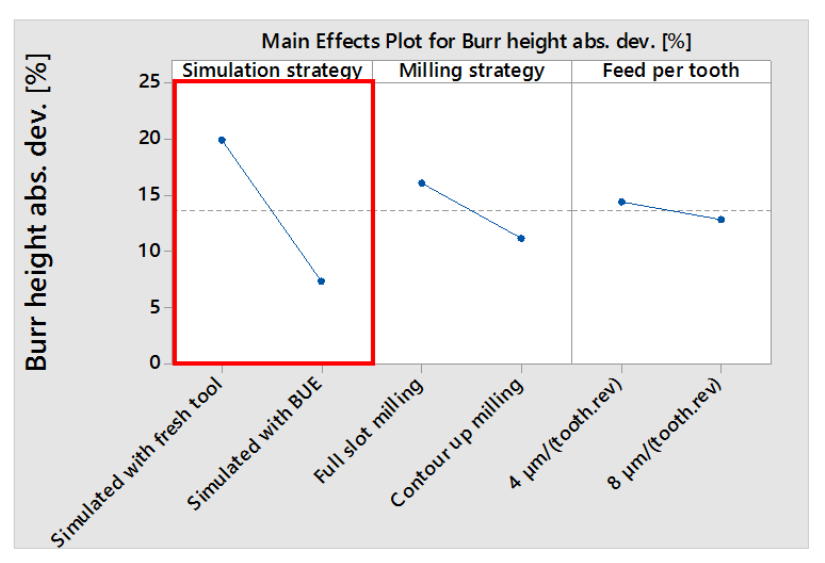

(c)

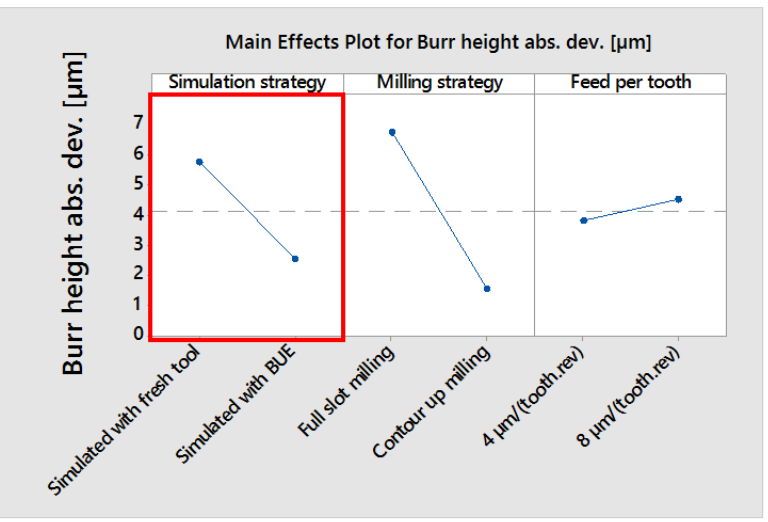

(d)

Fig. 10 (a) interaction plot burr height $[\mu \mathrm{m}]$ (b) interaction plot mean of burr height [\%] (c) main effects plot burr height [ $\mu \mathrm{m}]$ (d) main effects plot burr height $[\%]$

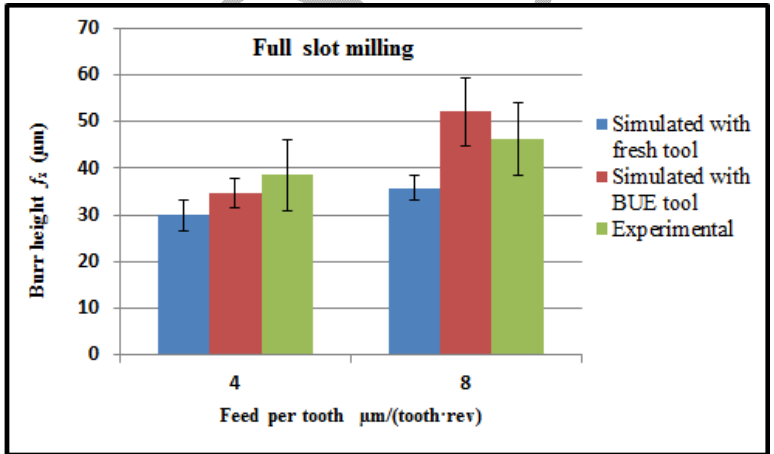

(a)

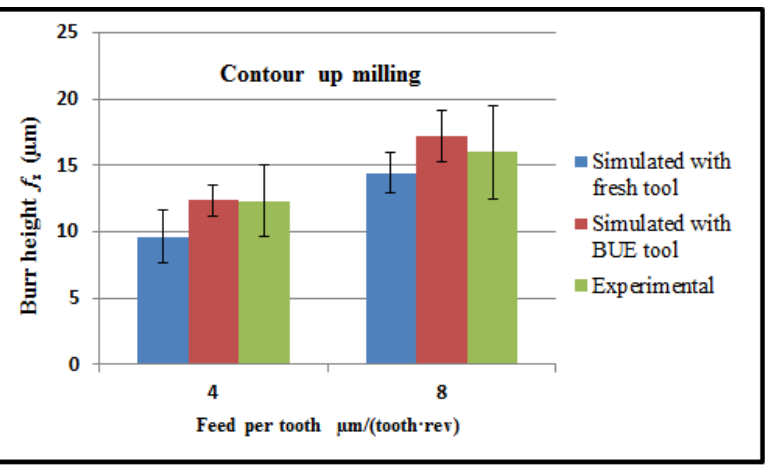

(b)

Fig. 9: Comparison of experimental and simulated burr height (a) full slot micro end-milling (b) contour up milling 


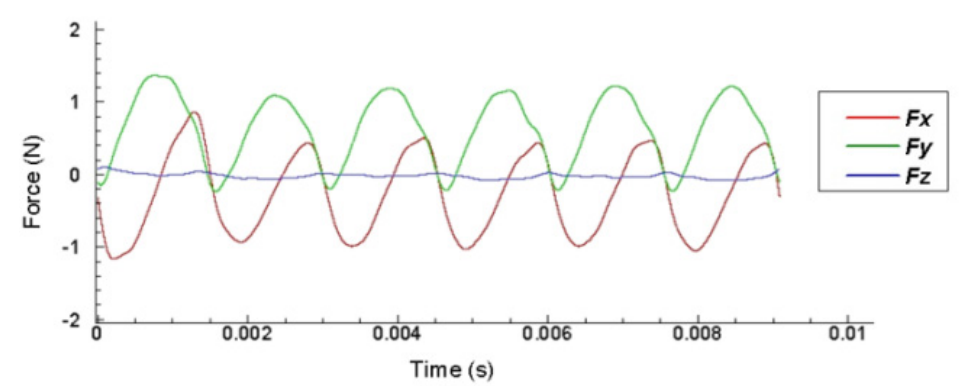

(a) FE cutting forces simulated with actual tool geometry

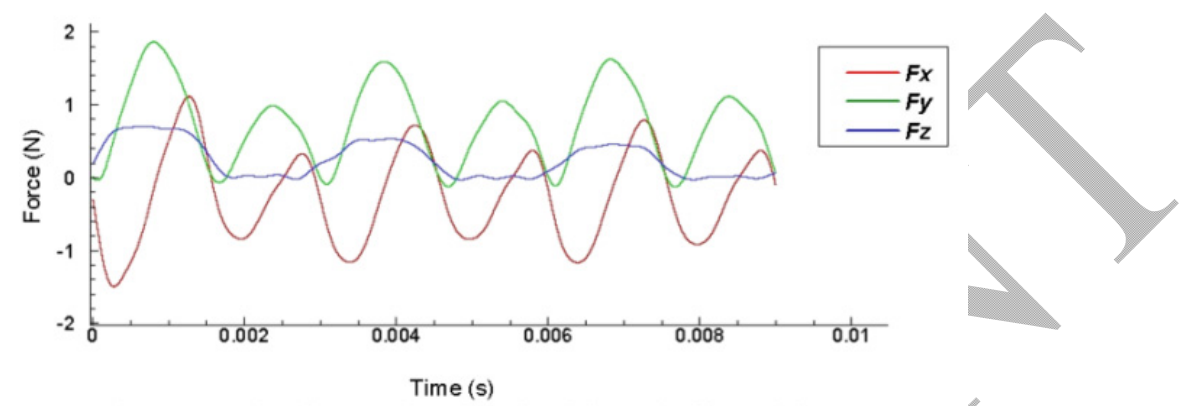

(b) FE cutting forces simulated with tool affected by BUE

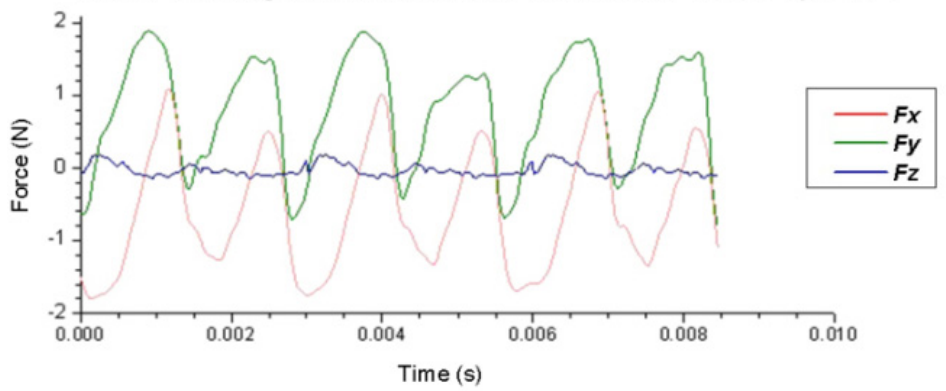

(c) Experimental cutting forces

Fig. 11: Cutting forces comparison for full slot micro end-milling at $f_{\mathrm{z}}=8 \mu \mathrm{m} /($ tooth $\cdot$ rev $)$

\section{Conclusion}

In this study, a 3D finite element simulation model of micro end-milling process of Al6082-T6 is developed. The 3D FE model shows the behavior of tools affected by built-up edge and consequent modified edge geometry, on the chip formation, burr generation and cutting forces. The FE prediction results obtained with the tool affected by BUE are compared against the FE simulations with actual tool geometry and micro endmilling experimental results. In terms of chip formation, different chip shapes are obtained in simulations with the same cutting conditions. Simulations confirm that the presence of BUE generates unequal chip load among different tooth engagements and different material removal from the workpiece. The simulation results of burr formation show that the BUE has a significant influence on the top burr height generation. In terms of cutting forces, the FE model affected by the BUE indicates dissimilar cutting forces in different engagements that were comparable by the experimentally measured cutting forces.

\section{Acknowledgment}

The research leading to these results has received funding from the People Programme (Marie Curie Actions) of the European Union's Seventh Framework Programme (FP7/2007 2013) under REA grant agreement no. 609405 (COFUNDPostdocDTU). The authors would also like to acknowledge the Politecnico di Milano university for founding the PhD project "3D Finite Element Modeling of Micro End Milling by Considering Tool Run-Out, Temperature Distribution, Chip and Burr Formation' by Ali Davudinejad. This research work was undertaken in the context of MICROMAN project ("Process Fingerprint for Zero defect Net shape MICROMANufacturing”, http://www.microman.mek.dtu.dk/). MICROMAN is a European Training Network supported by Horizon 2020, the EU Framework Programme for Research and Innovation (Project ID: 674801). 


\section{REFERENCES}

[1] T. Masuzawa, "State of the Art of Micromachining," CIRP Ann. - Manuf. Technol., vol. 49, no. 2, pp. 473-488, 2000.

[2] X. Liu, R. E. DeVor, S. G. Kapoor, and K. F. Ehmann, "The Mechanics of Machining at the Microscale: Assessment of the Current State of the Science,” J. Manuf. Sci. Eng., vol. 126, no. 4, pp. 666-678, Feb. 2005.

[3] A. Bhattacharyya, Metal cutting: theory and practice. New, 1984.

[4] Z. Pálmai and G. Csernák, "Effects of built-up edge-induced oscillations on chip formation during turning," J. Sound Vib., vol. 332, no. 8, pp. 2057-2069, 2013.

[5] Y. Ozcatalbas, "Chip and built-up edge formation in the machining of in situ Al4C3-Al composite," Mater. Des., vol. 24, no. 3, pp. 215221, 2003.

[6] J. C. Aurich, D. Dornfeld, P. J. Arrazola, V. Franke, L. Leitz, and S. Min, "Burrs-Analysis, control and removal," CIRP Ann. - Manuf. Technol., vol. 58, no. 2, pp. 519-542, 2009.

[7] S.-L. Ko, J.-E. Chang, and G.-E. Yang, "Burr minimizing scheme in drilling,” J. Mater. Process. Technol., vol. 140, no. 1, pp. 237-242, 2003.

[8] G.-L. Chern, "Experimental observation and analysis of burr formation mechanisms in face milling of aluminum alloys," Int. J. Mach. Tools Manuf., vol. 46, no. 12, pp. 1517-1525, 2006.

[9] D. Dornfeld, S. Min, and Y. Takeuchi, "Recent Advances in Mechanical Micromachining," CIRP Ann. - Manuf. Technol., vol. 55, no. 2, pp. 745-768, 2006.

[10] G. Kiswanto, D. L. Zariatin, and T. J. Ko, "The effect of spindle speed, feed-rate and machining time to the surface roughness and burr formation of Aluminum Alloy 1100 in micro-milling operation,” J. Manuf. Process., vol. 16, no. 4, pp. 435-450, 2014.

[11] D. Biermann and M. Steiner, "Analysis of Micro Burr Formation in Austenitic Stainless Steel X5CrNi18-10," Procedia CIRP, vol. 3, pp. 97-102, 2012.

[12] P. J. Arrazola, T. Özel, D. Umbrello, M. Davies, and I. S. Jawahir, "Recent advances in modelling of metal machining processes," CIRP Ann. - Manuf. Technol., vol. 62, no. 2, pp. 695-718, 2013.

[13] T. Özel and T. Altan, "Process simulation using finite element method - prediction of cutting forces, tool stresses and temperatures in high-speed flat end milling," Int. J. Mach. Tools Manuf., vol. 40, no. 5, pp. 713-738, 2000.

[14] A. Davoudinejad, P. Parenti, and M. Annoni, "3D finite element prediction of chip flow, burr formation, and cutting forces in micro endmilling of aluminum 6061-T6," Front. Mech. Eng., pp. 1-12, 2017.

[15] I. W. Park and D. A. Dornfeld, “A Study of Burr Formation Processes Using the Finite Element Method: Part I,” J. Eng. Mater. Technol., vol. 122, no. 2, pp. 221-228, Dec. 1999.

[16] I. W. Park and D. A. Dornfeld, "A Study of Burr Formation Processes Using the Finite Element Method: Part II—The Influences of Exit Angle, Rake Angle, and Backup Material on Burr Formation Processes," J. Eng. Mater. Technol., vol. 122, no. 2, pp. $229-237$, Dec. 1999.

[17] W. J. Deng, W. Xia, and Y. Tang, "Finite element simulation for burr formation near the exit of orthogonal cutting," Int. J. Adv. Manuf. Technol., vol. 43, no. 9, p. 1035, 2008.

[18] T. Thepsonthi and T. Özel, "Experimental and finite element simulation based investigations on micro-milling Ti-6Al-4V titanium alloy: Effects of cBN coating on tool wear," J. Mater. Process. Technol., vol. 213, no. 4, pp. 532-542, 2013.

[19] Y. C. Liang, K. Yang, Q. S. Bai, J. X. Chen, and B. Wang, "Modeling and experimental analysis of microburr formation considering tool edge radius and tool-tip breakage in microend milling," J. Vac. Sci. Technol. B Microelectron. Nanom. Struct., vol. 27, no. 3, p. 1531, 2009.

[20] M. J. Chen, H. B. Ni, Z. J. Wang, and Y. Jiang, "Research on the modeling of burr formation process in micro-ball end milling operation on Ti--6Al--4V,” Int. J. Adv. Manuf. Technol., vol. 62, no. 9, pp. 901-912, 2012.

[21] T. Thepsonthi and T. Özel, "3-D finite element process simulation of micro-end milling Ti-6Al-4V titanium alloy: Experimental validations on chip flow and tool wear,” J. Mater. Process. Technol., vol. 221, pp. 128-145, 2015.

[22] C. Maranhão and J. Paulo Davim, "Finite element modelling of machining of AISI 316 steel: Numerical simulation and experimental validation," Simul. Model. Pract. Theory, vol. 18, no. 2, pp. 139-156, 2010.

[23] A. Davoudinejad, E. Chiappini, S. Tirelli, M. Annoni, and M. Strano, "Finite Element Simulation and Validation of Chip Formation and Cutting Forces in Dry and Cryogenic Cutting of Ti-6Al-4V," Procedia Manuf., vol. 1, pp. 728-739, 2015.

[24] A. Maurel-Pantel, M. Fontaine, S. Thibaud, and J. C. Gelin, "3D FEM simulations of shoulder milling operations on a 304L stainless steel," Simul. Model. Pract. Theory, vol. 22, pp. 13-27, 2012.

[25] M. R. Movahhedy, Y. Altintas, and M. S. Gadala, "Numerical Analysis of Metal Cutting With Chamfered and Blunt Tools," J. Manuf. Sci. Eng., vol. 124, no. 2, pp. 178-188, Apr. 2002.

[26] S. Chatterjee, S. S. Mahapatra, and K. Abhishek, "Simulation and optimization of machining parameters in drilling of titanium alloys," Simul. Model. Pract. Theory, vol. 62, pp. 31-48, 2016.

[27] Advantedge, "Third Wave Advantedge user's manual," 2014.

[28] X. Man, D. Ren, S. Usui, C. Johnson, and T. D. Marusich, "Validation of Finite Element Cutting Force Prediction for End Milling," Procedia CIRP, vol. 1, pp. 663-668, 2012. 
[29] T. Özel, "The influence of friction models on finite element simulations of machining," Int. J. Mach. Tools Manuf., vol. 46, no. 5, pp. 518-530, 2006.

[30] M. K. Medaska, L. Nowag, and S. Y. Liang, "SIMULTANEOUS MEASUREMENT OF THE THERMAL AND TRIBOLOGICAL EFFECTS OF CUTTING FLUID,” Mach. Sci. Technol., vol. 3, no. 2, pp. 221-237, 1999.

[31] G. R. Johnson and W. H. Cook, "A constitutive model and data for metals subjected to large strains, high strain rates and high temperatures," 7th International Symposium on Ballistics. pp. 541-547, 1983.

[32] S. P. F. . Jaspers and J. . Dautzenberg, "Material behaviour in conditions similar to metal cutting: flow stress in the primary shear zone," J. Mater. Process. Technol., vol. 122, no. 2, pp. 322-330, 2002.

[33] A. Davoudinejad, "3D Finite Element Modeling of Micro End-Milling by Considering Tool Run-Out, Temperature Distribution, Chip and Burr Formation," University of Politecnico di Milano, 2016.

[34] G. Bissacco, H. N. Hansen, and J. Slunsky, "Modelling the cutting edge radius size effect for force prediction in micro milling," CIRP Ann. - Manuf. Technol., vol. 57, no. 1, pp. 113-116, 2008.

[35] A. Aramcharoen and P. T. Mativenga, "Size effect and tool geometry in micromilling of tool steel," Precis. Eng., vol. 33, no. 4, pp. 402407, 2009. 